\title{
Originals
}

\section{UK Prospective Study of Therapies of Maturity-Onset Diabetes}

\section{Effect of Diet, Sulphonylurea, Insulin or Biguanide Therapy on Fasting Plasma Glucose and Body Weight Over One Year}

\author{
Multi-centre study* \\ Radcliffe Infirmary, Oxford, Royal Infirmary, Aberdeen, General Hospital, Birmingham, St. George's Hospital and Hammersmith Hospital, \\ London and City Hospital, Belfast
}

\begin{abstract}
Summary. A multi-centre, prospective randomised study of the therapy of maturity-onset diabetes has been started, and we report progress of the first 286 patients with 1-year followup. Newly presenting patients (aged 25-65 years inclusive) were initially treated by diet and divided into three categories. (1) Forty-one patients $(14 \%)$ were 'primary diet failure' in that they continued to have symptoms or their fasting plasma glucose remained $>15 \mathrm{mmol} / 1$. Their therapy was allocated randomly to insulin, chlorpropamide or glibenclamide, and doses adjusted to try to maintain a fasting plasma glucose $<6 \mathrm{mmol} / 1$. Insulin produced a similar decrease in fasting plasma glucose to sulphonylurea therapy (median fasting plasma glucose fell from 15.4 to $8.0 \mathrm{mmol} / 1$ and from 15.5 to $8.6 \mathrm{mmol} / 1$, respectively). (2) After 3-4 months diet, 161 patients $(56 \%)$ were asymptomatic but had a fasting plasma glucose $>6 \mathrm{mmol} / 1$. In the 'main randomisation' their therapy was allocated to diet only, or diet plus chlorpropamide, glibenclamide or a basal insulin supplement from ultralente insulin. On diet alone, fasting plasma glucose remained constant over 1-year follow-up (from 7.7 to $7.6 \mathrm{mmol} / \mathrm{l}$ ), whereas it was reduced significantly by insulin (from 8.0 to 6.4 $\mathrm{mmol} / \mathrm{l})$, chlorpropamide $(8.6$ to $6.1 \mathrm{mmol} / \mathrm{l}$ ) and glibenclamide $(7.8$ to $6.5 \mathrm{mmol} / 1)$. On diet alone, weight remained un-
\end{abstract}

changed over 1 year but increased significantly on insulin, chlorpropamide or glibenclamide (median change ideal body weight $+3.5 \%,+4 \%$ and $+4 \%$, respectively). Obese patients ( $>20 \%$ over ideal weight) did not differ from normal weight diabetic subjects in either fasting plasma glucose or weight changes. Insulin therapy was associated with few hypoglycaemic episodes, with $8 \%$ of patients on ultralente insulin alone reporting an episode compared with $7 \%$ on chlorpropamide. Fifty-one patients $(86 \%)$ randomised to insulin remain on it 1 year later. (3) After 3-4 months on diet, 84 patients (30\%) after dieting had a fasting plasma glucose $<6 \mathrm{mmol} / \mathrm{l}$. During the following year on diet alone 34 patients were less well controlled with a fasting plasma glucose $>6 \mathrm{mmol} / 1$ and were in cluded in a 'delayed randomisation'. Thus $83 \%$ of all patients entered into the study had their therapy randomised by 1 year. Insulin and sulphonylurea therapy are equally effective in reducing glycaemia, and the study is being extended to determine if either therapy will prevent the complications of diabetes or have untoward long-term side effects.

Key words: Diabetes, therapy, diet, insulin therapy, sulphonylurea, biguanide, epidemiology, body weight, fasting plasma glucose.
At present, therapy of maturity-onset diabetes does not prevent complications, such as cardiovascular disease $[1-4]$ and retinopathy $[5,6]$. Control based on the ab-

\footnotetext{
* Co-ordinator: R.C.Turner; deputy co-ordinator: J. I. Mann; administrators: G. Iceton and S.Oakes; statistician: A. Smith; biochemist: J. Moore; physicians: R. C. Turner, T. D. R. Hockaday, R. R. Holman (Oxford), J.Stowers, M.Stowers, L. Murchison, L. Borthwick (Aberdeen), D. Wright, M. Fitzgerald, S.Gyde (Birmingham), T. Pilkington, N. Oakley, M. Whitehead (St. George's Hospital, London), E. Kohner, P.Lawson (Hammersmith Hospital, London), R. Hayes, W. Henry (Belfast); consultant statistician: R. Peto; consultant biochemist: A. Moore; consultant systems analyst: T. Stark; consultant dietitian: Miss L. Todd
}

sence of glycosuria may be insufficiently strict, as the renal threshold is often considerably above physiological glucose concentrations. The mean fasting plasma glucose of an unselected population monitored by glycosuria and treated by diet or tablets has been reported as $8 \mathrm{mmol} / \mathrm{l}[7]$.

Two major questions of clinical management are: (1) whether improved glycaemic control of maturity-onset diabetes would diminish the morbidity and mortality of the disease, and (2) whether it is preferable to lower the blood glucose concentrations with insulin or oral hypoglycaemic agents. The University Group Diabetes Programme (UGDP) suggested that tolbutamide and 


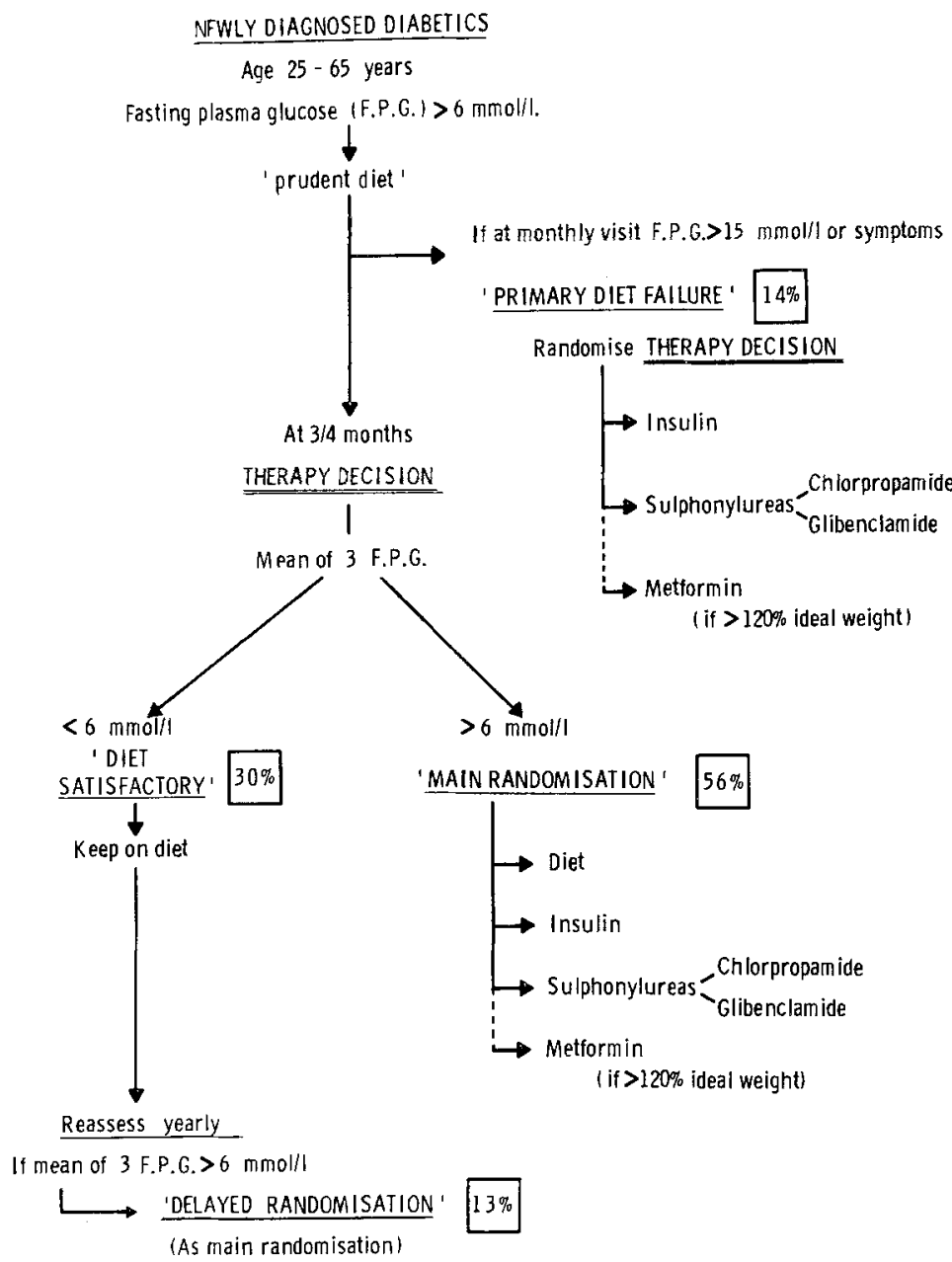

Fig. 1. Summary flow-chart of the main therapeutic groups. The figures in boxes denote the percentage of all patients entering study in that category. After Therapy Decision: patients seen 3-monthly (or more frequently if control poor). Main criteria of control: fasting plasma glucose and body weight. Therapy adjusted to aim for fasting plasma glucose $<6 \mathrm{mmol} / \mathrm{l}$ phenformin may be more harmful than beneficial [8]. This study provoked considerable controversy, and did not resolve the dilemma of what is the most appropriate therapy [9]. One reason for the lack of benefit of therapies in the UGDP trial might be that the criteria of control were insufficiently strict. Thus, even their most successful treatment, a variable dose of insulin, at the 35 th examination, gave a mean fasting blood glucose concentration of $6.7 \mathrm{mmol} / 1$ [10], representing approximately $7.8 \mathrm{mmol} / 1$ fasting plasma glucose.

A more logical criterion of control would be to aim for basal normoglycaemia, and this can be obtained with either ultralente insulin [11] or chlorpropamide [12]. The overnight basal plasma glucose concentration is relatively repeatable in a diabetic patient in a given nutritional state [13]. In practice it is reasonable to aim for a fasting plasma glucose of $<6 \mathrm{mmol} / 1$, and this means of control has been shown to be acceptable in an unselected group of maturity-onset diabetic patients [14], with a reduction of the raised fasting plasma glucose being accompanied by a reduced haemoglobin $\mathrm{A}_{1}$.

If, after dietary therapy, the fasting plasma glucose continues to be raised, there is little information available to determine whether one should continue with diet alone, or add sulphonylurea, biguanide or insulin.
The UK multi-centre prospective study is being undertaken to study this. The efficacy of these therapies in reducing the fasting plasma glucose, and their influence on body weight is reported. The study is being extended to determine whether any particular therapy or degree of improved control can prevent or reduce the morbidity and excessive mortality of the disease.

\section{Methods}

\section{Entry to Study}

Patients aged 25-65 years inclusive with recently diagnosed diabetes (main criterion fasting plasma glucose $>6 \mathrm{mmol} / 1$ on two occasions) were asked if they wished to participate in a prospective study. They were told that there is uncertainty which therapy is best if diet alone fails to control their diabetes, and that the decision would then be randomised. Exclusions were patients with ketonuria, myocardial infarction in the previous year, angina, heart failure, more than one major vascular episode, serum creatinine $>175 \mu \mathrm{mol} / 1$, severe retinopathy requiring photocoagulation, malignant hypertension, an uncorrected endocrine abnormality, an occupation which would not allow randomisation to insulin therapy (e.g. heavy goods vehicle driver), a severe intercurrent illness likely to limit life (e.g. cancer), or requiring extensive systemic treatment (e.g. ulcerative colitis), and inadequate comprehension to allow co-operation. If reasonable, diuretics and oestrogen therapy were stopped before assessment. 


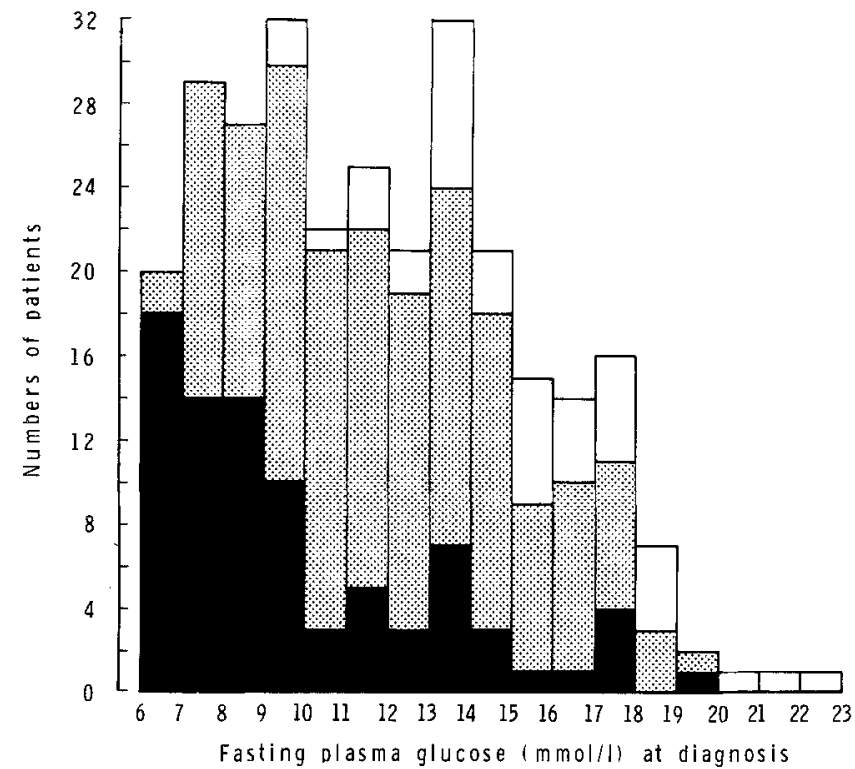

Fig. 2. Histogram of fasting plasma glucose concentrations of patients at their first clinic visit. The subsequent category of patients after dietary advice is shown by shading. Key: $\mathbf{\square}$ : diet satisfactory; $\square$ : main randomisation; $\square$ : primary diet failures
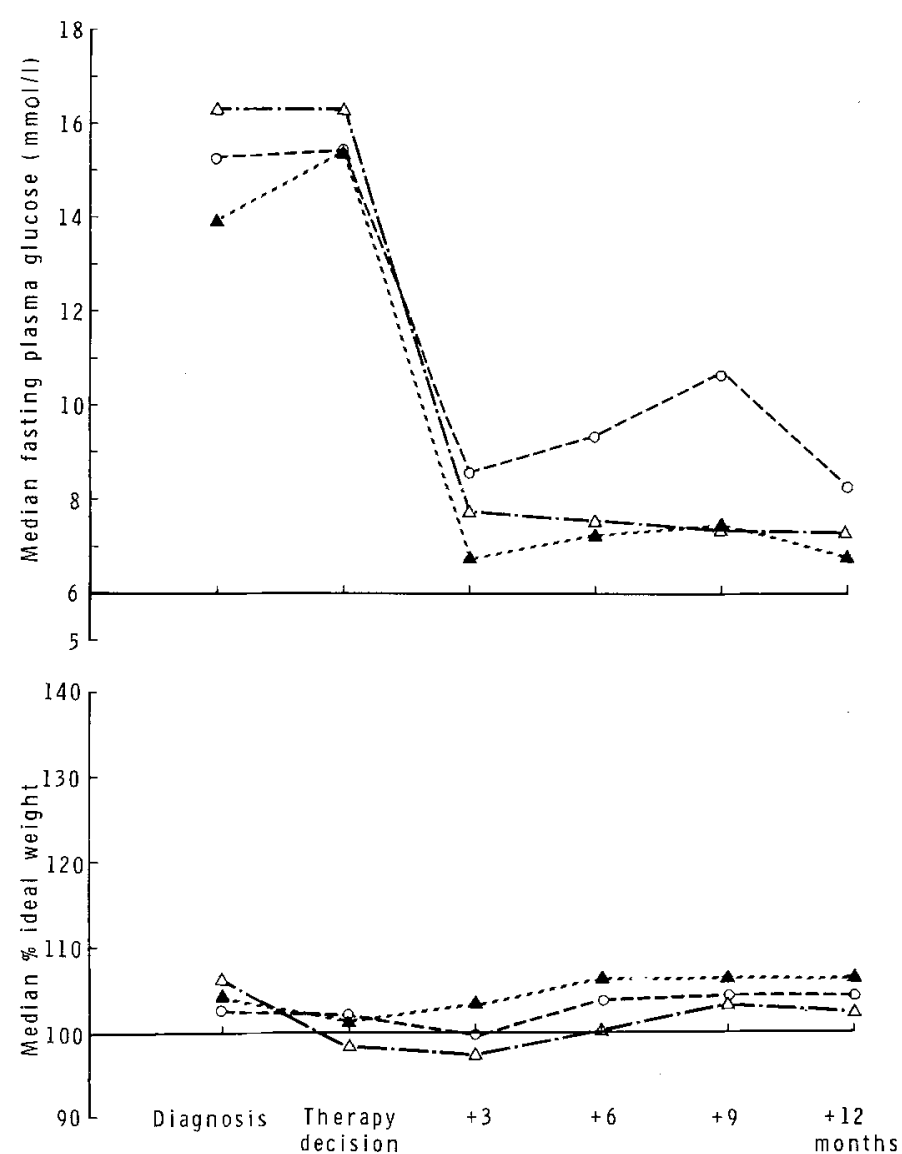

Fig.3. Median fasting plasma glucose concentrations and body weight of the normal weight patients ( $<20 \%$ over ideal weight) who could not be controlled on diet because of persistent fasting plasma glucose $>15 \mathrm{mmol} / \mathrm{l}$ or symptoms, e.g. thirst ('primary diet failure'). The patients on insulin $(n=17, \Delta)$ had a similar decrease in fasting plasma glucose to the patients allocated to sulphonylurea $(10 \mathrm{chlor}-$ propamide $O$; seven glibenclamide $\Delta$ ), five of whom had failed on oral therapy and had been transferred to insulin

\section{Therapy Decisions}

Patients were advised to take a 'prudent' diet, containing approximately 50\% carbohydrate, low saturated fat and moderately high fibre, of energy content to attain ideal body weight [15]. They were initially seen at monthly intervals, usually by a dietitian as well as a doctor.

\section{Main Randomisation}

At 3 months, three fasting plasma glucose estimations were taken for a 'therapy decision'. If the mean was $>7 \mathrm{mmol} / \mathrm{l}$, patients were randomised according to a decision in a sealed envelope with stratification according to whether the weight was $<$ or $>20 \%$ over ideal weight [15]. If the fasting plasma glucose was borderline $(6-7 \mathrm{mmol} / 1)$ the patient was kept on diet alone for a further month and then randomised if a mean of two fasting plasma glucose concentrations was $>6 \mathrm{mmol} / \mathrm{l}$. In this 'main randomisation', non-obese patients were randomised to: $30 \%$ diet alone, $30 \%$ insulin, $20 \%$ chlorpropamide and $20 \%$ glibenclamide. Obese patients had the same proportional allocation with an additional group randomised to metformin (proportions: $24 \%$ diet alone, $24 \%$ insulin, $16 \%$ chlorpropamide, $16 \%$ glibenclamide, $20 \%$ metformin: Fig. 1).

Insulin therapy: Patients randomised to insulin were started on ultralente insulin (beef Ultratard MC, Novo), the initial dose being calculated by subtracting three from the fasting plasma glucose in $\mathrm{mmol} / \mathrm{l}$, and multiplying by two to give the dose in units/day, with an increase of $x$ (actual weight/ideal weight) ${ }^{2}$ if the patient was obese [11]. Patients were asked to maintain their normal 'prudent' diet, but were not given specific rules on the size or timing of meals as usually required with short-acting insulin therapy. Patients were provided with disposable insulin syringes, and seen at 1- or 2-weekly intervals when the insulin dose was adjusted until the fasting plasma glucose became $<$ $6 \mathrm{mmol} / 1$, and thereafter at regular 3-monthly intervals. If the patient was receiving more than $12 \mathrm{U} /$ day ultralente insulin, he was asked to do home blood glucose monitoring. If the pre-meal or pre-bed blood glucose concentrations were $>7 \mathrm{mmol} / 1$, the patient was put onto an ultralente and twice daily soluble insulin regime [17], although other insulins could be used if glucose control was not satisfactory.

Oral hypoglycaemic agents: Doses were increased at 1- or 2-weekly intervals, until the fasting plasma glucose became $<6 \mathrm{mmol} / \mathrm{l}$, to a maximum for chlorpropamide $500 \mathrm{mg}$ once daily, for glibenclamide $10 \mathrm{mg}$ twice daily [16] and for metformin $1700 \mathrm{mg}$ at breakfast and $850 \mathrm{mg}$ at the evening meal. Once a patient had a fasting plasma glucose of $<$ $6 \mathrm{mmol} / 1$, or was on maximum therapy, 3-monthly appointments were given. If on a sulphonylurea either the fasting plasma glucose became $>15 \mathrm{mmol} / 1$ or symptoms developed, metformin was added. If either of these criteria persisted the patient was put on to insulin therapy. Patients randomised to metformin, who became poorly controlled by the same criteria, had additional glibenclamide therapy before transferring to insulin.

\section{Primary Diet Failure}

During the initial 3 months on diet, if either the fasting plasma glucose remained $>15 \mathrm{mmol} / 1$ or symptoms (e.g. polyuria or thirst) persisted, a 'therapy decision' termed 'primary diet failure' was made using a separate series of randomisation envelopes from the 'main randomisation'. The same obesity stratification and proportional allocation to therapies applied except for the absence of a 'diet only' group.

\section{Delayed Randomisation}

If after the initial 3 or 4 months of diet the fasting plasma glucose fell to $6 \mathrm{mmol} / 1$ or less, the patient was deemed 'diet satisfactory', was kept on diet alone and, like other patients in the study, seen at 3- 
Table 1. Patient data at presentation

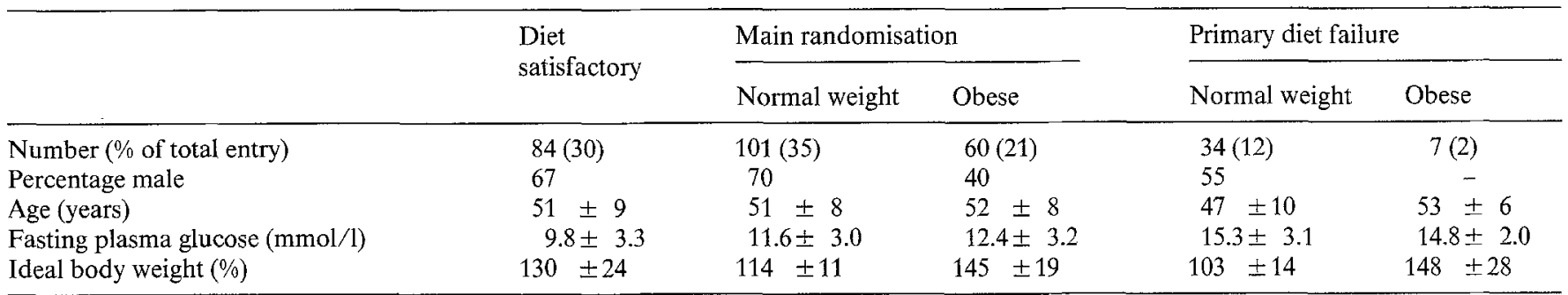

Results expressed as mean $\pm \mathrm{SD}$
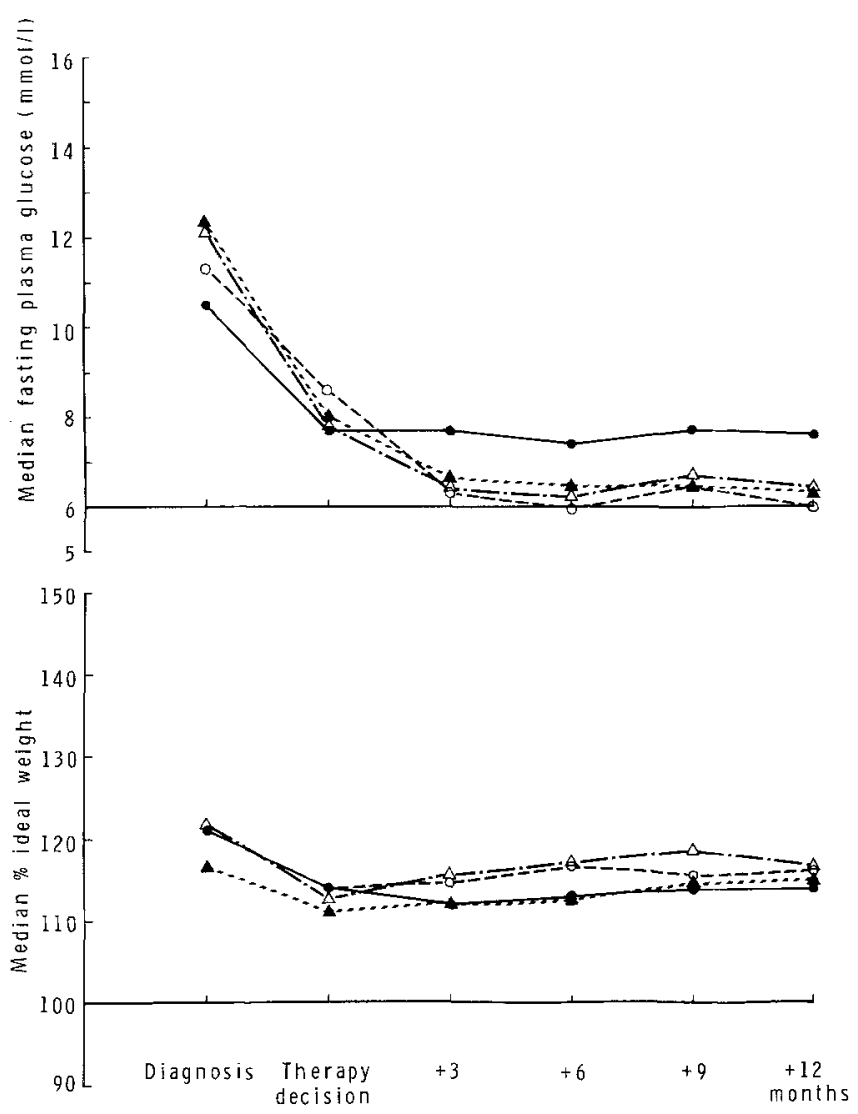

Fig. 4. The median fasting plasma glucose and body weight of patients who were asymptomatic on diet therapy, but whose fasting plasma glucose remained $>6 \mathrm{mmol} / 1$ ("main randomisation'). The patients allocated to insulin $(n=42, \mathbf{\Delta})$ or sulphonylurea ( 26 chlorpropamide $0 ; 33$ glibenclamide $\Delta$ ) had a significant reduction in mean fasting plasma glucose, whereas there was no change in the patients allocated to diet alone $(n=49$,

\section{General Arrangements}

Each centre was provided with additional doctor and nurse sessions to assist with the study. If feasible, female hormone therapy was avoided. Guidelines were set for management of patients on diuretics (avoid thiazides), hypertension (treat if diastolic $>100 \mathrm{mmHg}$ ) and hyperlipidaemia (treat if cholesterol $>8.5 \mathrm{mmol} / 1$ or fasting triglyceride $>4.0 \mathrm{mmol} / \mathrm{l}$ ). Special arrangements were made for ophthalmological examination including retinal photography, regular blood pressure measurements, assessments of diabetic complications, and notification of any complications or drug reactions. All data were put onto computer-compatible sheets, and 'punched' twice for verification. Randomisation envelopes were prepared with their decision determined by a computer program. An envelope was only opened when a decision was needed and the date of opening, result and patient number were then placed on the envelope for computing in $\mathrm{Ox}$ ford. A 'checking program' checked the randomisation dates and results and excluded gross data errors for all variables. An 'accounting program' checked patient visits and data reception and requested missing data from the centres. Bias in measurement of fasting plasma glucose was monitored by sending to each centre every month four commercial quality control samples with values between 5 and $17 \mathrm{mmol} / \mathrm{l}$. For each sample the mean of the results for all centres was calculated and each result expressed as a percentage of that mean. All values from each centre over 6 months were averaged, and the percentage bias ranged from -3.4 to $+6.2 \%$. Centres tended to maintain the direction of their bias.

\section{Analyses}

Computation was done by the full time statistician on a CTL 8050 computer (Computer Technology, Hemel Hempstead, UK). Obesity was expressed relative to the ideal body weight according to the mean of middle frame subjects [15]. Weight change was expressed from 'therapy decision' to 1 year. Fasting plasma glucose changes were expressed from the mean of the three values at 'therapy decision' to the mean of the three values at 6,9 and 12 months later. All statistics were according to the assigned groups at 'therapy decision', irrespective of non-compliance or subsequent therapy changes [18], and used the Mann-Whitney test for non-parametric data.

\section{Results}

So far 777 patients have been recruited, and this paper reports the results on the 286 who have been followed for 1 year from the major 'therapy decision'. They had a mean age of 51 years, mean ideal weight was $125 \%$, mean fasting plasma glucose at the first clinic visit $11.4 \mathrm{mmol} / 1$, and $59 \%$ were male. Figure 2 shows the fasting plasma glucose at the first clinic visit and Table 1 summarises the patients in the major categories. 

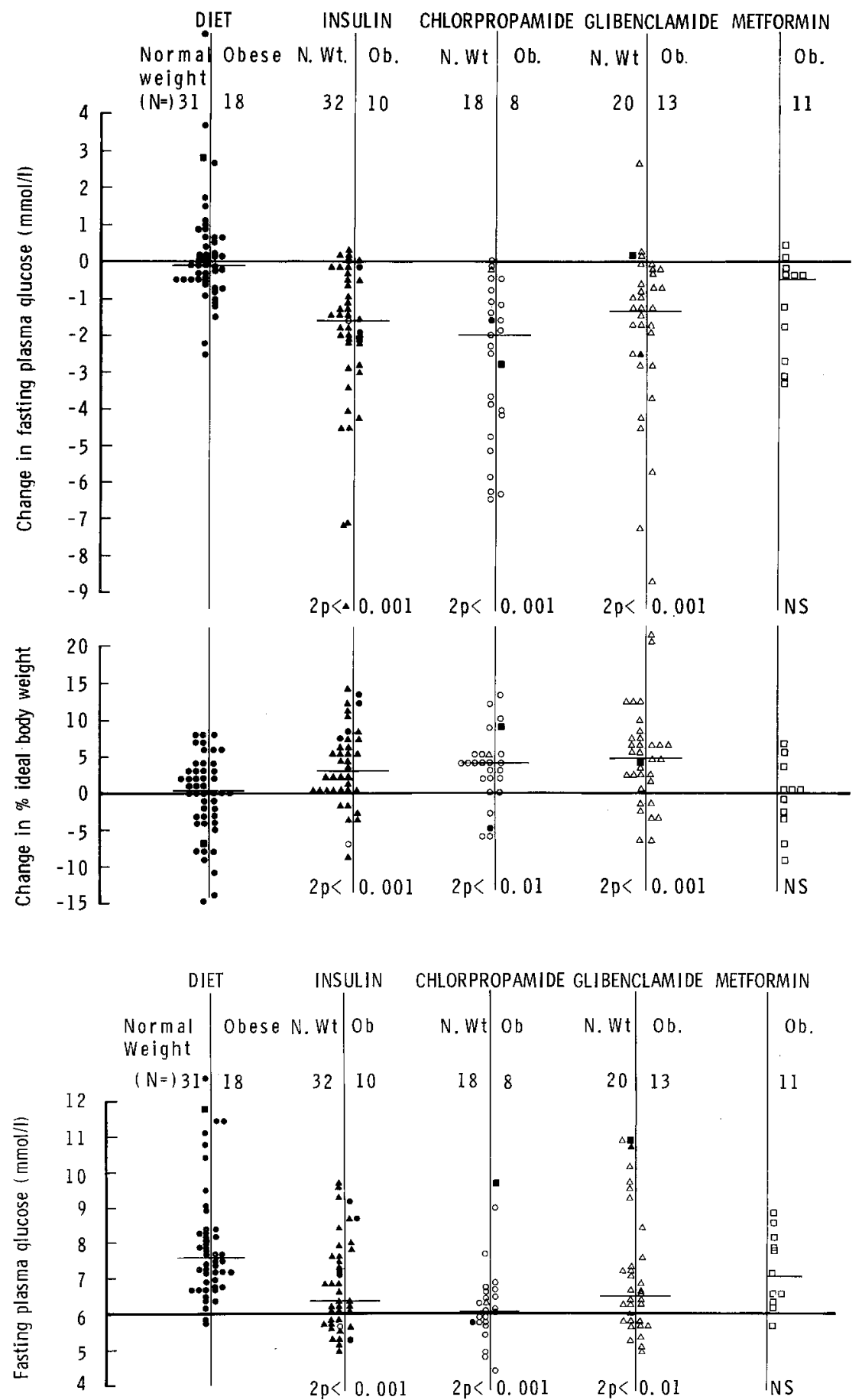

Fig.5. Change in fasting plasma glucose and body weight in the normal weight and obese ( $>20 \%$ over ideal body weight) subjects whose fasting plasma glucose was $>6 \mathrm{mmol} / 1$ after 3-4 months diet and who were then randomly allocated to different therapies 'main randomisation'. The plasma glucose values are from 'therapy decision' to mean of $+6,+9$ and +12 months later, and the percentage ideal weight from 'therapy decision' to 12 months later. The actual therapy is denoted by the symbols: $=$ diet alone, $\Delta=$ insulin, $O=$ chlorpropamide, $\Delta=$ glibenclamide, $\mathbf{\square}=$ sulphonylurea + metformin, $\square=$ metformin. The horizontal lines denote the median for each therapy allocation. The significance values compare each therapy group with 'diet only'
Fig. 6. Plasma glucose control as measured by the mean fasting plasma glucose of normal weight and obese patients $+6,+9$ and +12 months after 'main randomisation'. See Figure 5 for further details

\section{Primary Diet Failure}

Forty-one patients $(14 \%)$ were 'primary diet failures' with 38 having continued symptoms and 28 a fasting plasma glucose $>15 \mathrm{mmol} / 1$. They were less obese than the other groups, and had a higher initial fasting plasma glucose. Fifteen of 17 non-obese patients on sulphonylurea therapy had the dose increased to the maximum. Six of the 10 non-obese patients randomised to chlorpropamide and two of the seven randomised to glibenclamide therapy continued by the same criteria to be 'tablet failures' and had metformin added. Four pat- ients on chlorpropamide and metformin and one on glibenclamide and metformin continued as "tablet failure' and were transferred to insulin within 1 year. Nine of the 17 non-obese patients randomised to insulin needed soluble as well as ultralente insulin, the mean total daily insulin dose at 1 year of all 17 patients was 31 units.

The patients assigned to insulin therapy had a similar fasting plasma glucose concentration (mean after 6 , 9 and 12 months) to the combined sulphonylurea groups (median 8.0 and $8.6 \mathrm{mmol} / 1$, respectively; Fig. 3). 

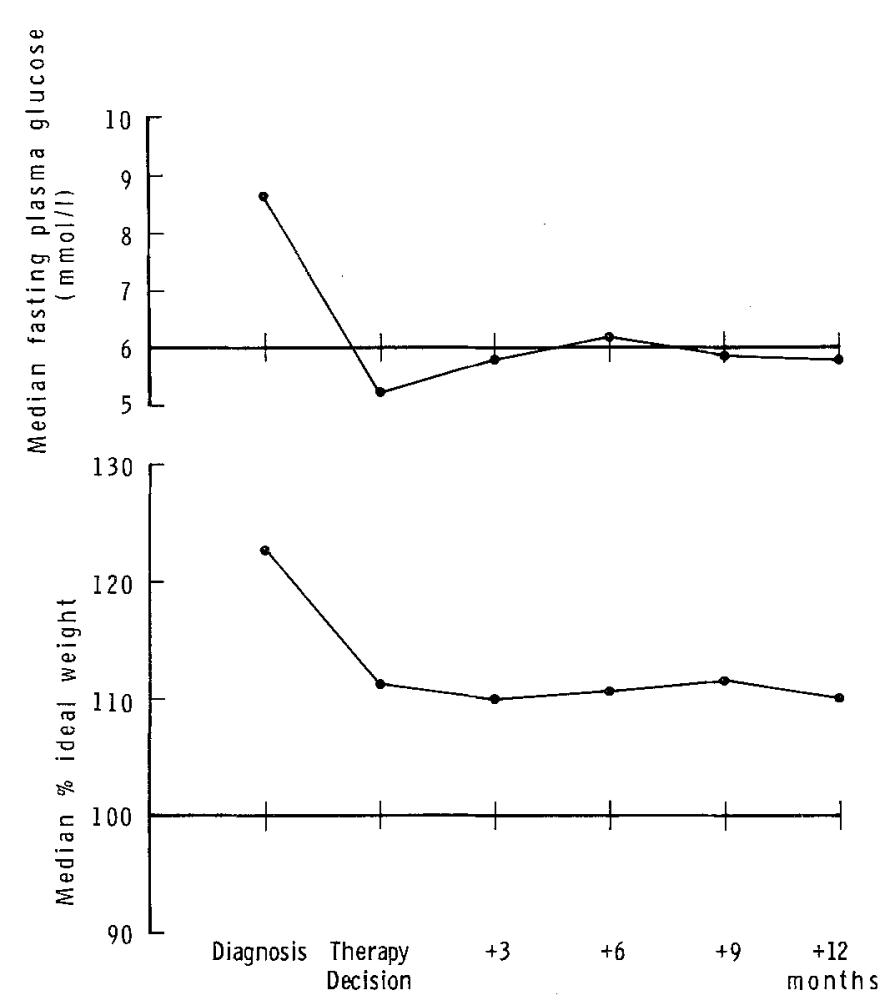

Fig. 7. Median fasting plasma glucose and body weight in the patients who were initially controlled by diet (i.e. fasting plasma glucose became $<6 \mathrm{mmol} / 1$ ). Subsequently the fasting plasma glucose rose significantly even though they dieted sufficiently to maintain a reduced body weight (although usually they were on a less restricted diet than previously). Forty percent of these patients had a 'delayed randomisation' at 1 year because the mean of the $+6,+9$, and +12 month fasting plasma glucose was $>6 \mathrm{mmol} / 1$

\section{Main Randomisation}

One hundred and sixty-one patients (56\%) were asymptomatic after 3-4 months on diet, although the mean of three fasting plasma glucose concentrations remained $>6 \mathrm{mmol} / 1$. Figure 4 shows the median fasting plasma glucose of the groups of patients allocated to each therapy. Four of the 42 patients randomised to insulin were put on soluble insulin in addition to ultralente. On diet alone, the fasting plasma glucose remained constant over 1 year follow-up (from median 7.7 to $7.6 \mathrm{mmol} / 1)$ whereas it was reduced by insulin (median 8.0 to $6.4 \mathrm{mmol} / \mathrm{l}$ ), chlorpropamide (median 8.6 to $6.1 \mathrm{mmol} / \mathrm{l}$ ) and glibenclamide (median 7.8 to $6.5 \mathrm{mmol} / \mathrm{l}$ ); each $2 p<0.01$ different from the diet only group. The obese patients randomised to metformin had a slightly smaller fall in fasting plasma glucose (median 8.4 to $7.1 \mathrm{mmol} / \mathrm{l}$ ) than those on insulin or sulphonylurea.

The change in fasting plasma glucose from the "therapy decision' to the mean of 6,9 and 12 months later is shown in Figure 5. There was no difference in the response of the normal weight or obese subjects to the different treatments. Those randomised to continue with diet alone had little change in fasting plasma glucose, whereas those also treated with insulin, chlorpropamide or glibenclamide had a similar decrease in fasting plasma glucose. The mean levels of 6,9 and 12 months fasting plasma glucose of patients after 1 year are shown in Figure 6 . Whereas only $27 \%$ of 'diet only' patients had a fasting plasma glucose $<7 \mathrm{mmol} / 1,60 \%, 77 \%$ and $58 \%$ of patients on insulin, chlorpropamide and glibenclamide respectively had a fasting plasma glucose < $7 \mathrm{mmol} / 1$ (each $\mathrm{p}<0.01$ compared with the diet only group - Chi-square test).

Insulin and the two sulphonylureas caused a slight but significant increase in weight after 1 year, the median being $+2 \mathrm{~kg}$ greater than those randomised to diet alone. Metformin did not increase body weight. The mean daily doses of insulin, chlorpropamide, glibenclamide and metformin after 6 and 12 months were $17 \mathrm{U}$ and $19 \mathrm{U}, 282 \mathrm{mg}$ and $301 \mathrm{mg}, 6.7 \mathrm{mg}$ and $7.6 \mathrm{mg}$, and $1636 \mathrm{mg}$ and $1717 \mathrm{mg}$, respectively. Fifty-one of 59 patients $(86 \%)$ randomised to insulin and followed for 1 year accepted it and remained on it.

\section{Diet Satisfactory}

Eighty-four patients (30\%) after the initial 3 or 4 months on diet had a mean fasting plasma glucose of < $6 \mathrm{mmol} / \mathrm{l}$. Most subsequently had a higher fasting plasma glucose (Fig. 7). In anticipation of the delayed randomisation at 1 year, there was a slight fall in fasting plasma glucose, but $34(40 \%)$ had a mean of the last three fasting plasma glucose of $>6 \mathrm{mmol} / \mathrm{l}$, and were randomised at 1 year in an identical way to the other patients at the major 'therapy decision'. Thus, a total of $83 \%$ of all patients entered into the study had their therapy randomised by the end of the first year.

\section{Side Effects}

Few side effects of therapy were noted. Hypoglycaemic reactions are difficult to assess, but physicians thought that seven of the 13 patients ( $54 \%$ ) on more complex insulin regimes, including short-acting insulin, had hypoglycaemic reactions. Only three of the 38 patients $(8 \%)$ treated with ultralente insulin alone had reactions, usually after exercise, and never requiring hospital admission. Eleven patients $(31 \%)$ on glibenclamide and two patients on chlorpropamide therapy $(7 \%)$ had mild hypoglycaemic reactions. Five of the 12 patients on metformin had gastro-intestinal side effects requiring a reduction in dose. Two of the 39 patients randomised to chlorpropamide had alcohol-induced flushing and one a skin rash.

\section{Discussion}

These results suggest that a multi-centre, prospective randomised study of maturity-onset diabetes is feasible. Aiming to lower the fasting plasma glucose concentra- 
tion to $<6 \mathrm{mmol} / 1$ proved to be a safe and acceptable way of monitoring therapy. Insulin treatment, with a basal insulin supplement provided by ultralente insulin, was a practical alternative to sulphonylurea. The small risk of hypoglycaemia, the absence of the usual need with insulin therapy for strict portions of food at specific meals, and the simplicity of injections with modern disposable insulin syringes, assisted patient acceptance of this treatment. Insulin is often thought to be contraindicated in maturity-onset diabetes, because it might induce excessive weight gain. However, the increase in weight was similar to that induced by sulphonylurea therapy, and both after 1 year were associated with a median weight gain of only $2 \mathrm{~kg}$ compared with no change in the diet only group. Insulin and sulphonylureas were similarly effective in reducing the fasting plasma glucose. The reduction of median fasting plasma glucose in this study by insulin or sulphonylurea was nearly twice that achieved by the UGDP study at the same stage $[8,10]$. Metformin was only used in the obese patients, and appeared to have less hypoglycaemic effect than the other additional therapies but did not increase body weight.

Patients with diabetes have an increased incidence of death from cardiovascular disease [1] and even minimal glucose intolerance, approximately equivalent to a fasting plasma glucose of $5.5-6.0 \mathrm{mmol} / \mathrm{l}$, is associated with increased cardiac mortality [2-4]. The risk of diabetic retinopathy is not great until the 2 -h plasma glucose after a $50 \mathrm{~g}$ oral glucose load is $11 \mathrm{mmol} / 1$ [5], which is equivalent to the fasting plasma glucose of $>7.7 \mathrm{mmol} / 1$ suggested by a subsequent study [6]. As, in the present study, the majority of patients randomised to insulin or sulphonylurea after 1 year have a fasting plasma glucose below this level, but most of those randomised to diet are above this level, it should be possible to determine whether improved glycaemic control will prevent retinopathy.

The study is being extended to recruit 3,500 patients in 15 centres to investigate whether insulin, sulphonylurea or biguanide therapy might reduce the incidence of complications, including macrovascular events or retinopathy, nephropathy or peripheral neuropathy. It should be possible to determine whether sulphonylurea therapy produces untoward side effects, as suggested by the UGDP study. That study has been criticised for analysing data according to the treatment groups to which patients were assigned, regardless of adherence to therapy. As a general principle, that is correct as deviants from a group tend not to be randomly selected, and analysis of subgroups can lead to bias. Nevertheless, such an analysis has suggested that patients given insulin in variable dosage to optimise glucose control might have had a decrease in cardiovascular mortality $[19,20]$ and that tolbutamide might only be associated with increased mortality if the fasting blood glucose remains greater than $11.1 \mathrm{mmol} / 1(200 \mathrm{mg} / \mathrm{dl})$ [21]. Certainly, studies of tolbutamide therapy in borderline diabetic patients have not indicated an increased cardiovascular mortality $[22,23]$.

The overall aims of the present study are (1) to provide data concerning the effects of the different treatments on clinical and biochemical aspects of diabetes, which might guide clinicians in their choice of therapy, and (2) to indicate the degree of plasma glucose control, for which it would be advisable to aim, to prevent the complications of the disease.

Acknowledgements. We are grateful to the Oxford Medical School Research Fund and the Charles Wolfson Charitable Trust for grants for the initial studies, and to the Clothworkers' Foundation, Hoechst, British Diabetic Association, Novo, Boehringer Mannheim, Rona, Roussel, Pfizer, The Hilden Charitable Trust, The Alan and Babette Sainsbury Charitable Fund, Rothman, British Petroleum, Rank Hovis McDougall, Unigate, Monsanto, Kodak, Pilkington, Legal and General, Kenning, Xerox, Chloride, Cable and Wireless, Blue Circle Industries, BPB Industries, The Steetley Company, George Wimpey, and The Prudential Assurance for grants. Becton Dickinson provided disposable SFP insulin syringes and Hoechst provided data sheets.

\section{References}

1. Garcia MJ, McNamara PM, Gordon T, Kannell WB (1974) Morbidity and mortality in diabetics in the Framingham population. Sixteen year follow-up. Diabetes 23: 105-111

2. Stamler R, Stamler J (1979) Asymptomatic hyperglycaemia and coronary heart disease. J Chron Dis 32: 683-837

3. Fuller JH, Shipley MJ, Rose G, Jarrett RJ, Keen H (1980) Coronary-heart-disease risk and impaired glucose tolerance. The Whitehall study. Lancet 1: 1373-1376

4. Eschwege E, Ducimetiere P, Papoz L, Claude JR, Richard JL (1980) Blood glucose and coronary heart disease. Lancet 2: $472-473$

5. Jarrett RJ, Keen H (1976) Hyperglycaemia and diabetes mellitus. Lancet 2: 1009-1012

6. Pettit DJ, Knowler WC, Lisse JR, Bennett PH (1980) Development of retinopathy and proteinuria in relation to plasma glucose concentrations in Pima Indians. Lancet 2: 1050-1052

7. Howe-Davies S, Holman RR, Phillips M, Turner RC (1978) Home blood sampling for plasma glucose assay in control of diabetes. $\mathrm{Br}$ Med J 2: 596-598

8. University Group Diabetic Programme (1976) A study of the effects of hypoglycaemic agents on vascular complications in patients with adult-onset diabetes. Diabetes 25: 1129-1153

9. Whitehouse FW, Arky RA, Bell DI, Lawrence PA, Freinkel N (1979) Policy statement. The university group diabetic programme controversy. Diabetes $28: 168-170$

10. Knatterud GL, Klimt CR, Levin ME, Jacobson ME, Goldner MG (1978) Effects of hypoglycaemic agents on vascular complications in patients with adult-onset diabetes. VII. Mortality and selected nonfatal events with insulin treatment. JAMA $240: 37-42$

11. Holman RR, Turner RC (1977) Diabetes: The quest for basal normoglycaemia. Lancet 1: 469-474

12. Holman RR, Turner RC (1978) Basal normoglycaemia attained with chlorpropamide in mild diabetes. Metabolism 27:539-547

13. Holman RR, Turner RC (1979) Maintenance of basal plasma glucose and insulin concentrations in maturity-onset diabetes. Diabetes $28: 227-230$

14. Howe-Davies S, Simpson RW, Turner RC (1980) Control of maturity-onset diabetes by monitoring fasting blood glucose and body weight. Diabetes Care 3: 607-610

15. Metropolitan Life Insurance Company (1959) Net weight standard for men and women. Stat Bull 40: Nov-Dec 1-4

16. Ward EA, Lang DA, Phillips MR, Turner RC (1981) Comparison 
of chlorpropamide and glibenclamide treatment of maturity-onset diabetes: Control assessed by fasting plasma glucose concentrations. Diabetes Care 4: 293-295

17. Phillips M, Simpson RW, Holman RR, Turner RC (1979) A simple and rational twice daily insulin regime. Quart $\mathrm{J}$ Med 48: 493-506

18. Peto R, Pike MC, Armitage P, Breslaw NE, Cox PR, Howard SV, Mantel N, McPherson K, Peto J, Smith PG (1977) Design and analysis of randomised clinical trials requiring prolonged observations of each patient. Br J Cancer 35: 1-39

19. Kilo C, Williamson JR, Choi SC, Miller JP (1979) Refuting the University Group Diabetic Programme conclusion that insulin treatment does not prevent vascular complications in diabetes. Adv Exp Med Biol 119: 307-311

20. The University Group Diabetes Program (1982) VIII Evaluation of Insulin Therapy: Final Report. Diabetes 31 (Suppl 5): 1-26

21. Kilo C, Miller JPh, Williamson JR (1980) The crux of the university group diabetic programme. Spurious results and biologically inappropriate data analysis. Diabetologia 18: 179-185
22. Keen H, Jarrett RJ, Fuller JH (1973) Tolbutamide and arterial disease in borderline diabetics. Excerpta Med Int Congr Ser 312: $588-602$

23. Sartor G, Schersten B, Carlström S, Melander A, Norden A, Persson $G$ (1980) Ten-year follow-up of subjects with impaired glucose tolerance. Prevention of diabetes by tolbutamide and diet regulation. Diabetes 29: 41-49

Received: 4 May 1982

and in revised form: 7 March 1983

Dr. R.C.Turner

Diabetes Research Laboratories

Nuffield Department of Clinical Medicine

Radcliffe Infirmary

Woodstock Road

Oxford, OX2 6HE, UK 